\title{
EMOTIONAL INTELLIGENCE DAN STRES PADA MAHASISWA YANG MENGALAMI QUARTER-LIFE CRISIS
}

\author{
Akta Ririn Aristawati', Tatik Meiyuntariningsih ${ }^{2}$, Firmansyah Dwi \\ Cahya $^{3}$, Ananda Putri 4 \\ Email: akta_ririn@untag-sby.ac.id ${ }^{1}$ \\ Universitas 17 Agustus 1945 Surabaya ${ }^{1,2,3,4}$
}

\begin{abstract}
Abstrak
Tujuan dari penelitian ini adalah mengetahui hubungan antara tingkat emotional intelligence dengan tingkat stres pada mahasiswa yang mengalami quarter life crisis. Adapun hipotesa yang diajukan adalah adanya hubungan negatif antara tingkat emotional intelligence dengan tingkat stres pada mahasiswa yang mengalami quarter life crisis. Penelitian ini merupakan penelitian kuantitatif yang melibatkan 100 mahasiswa yang masih berada pada masa dewasa awal dengan rentang usia 20 hingga 30 tahun. Pengumpulan data dilakukan dengan menggunakan 2 skala yaitu skala emotional intelligence dan stress. Data tersebut dianalisis menggunakan program Statistic Package for Social Science 25 for windows version dengan teknik korelasi product moment. Hasil analisa data menunjukkan nilai korelasi sebesar -0,643 dengan taraf signifikansi 0,000 $(\mathrm{p}<0,05)$. Hal ini dapat diartikan bahwa emotional intelligence berhubungan negatif dan signifikan terhadap stres pada mahasiswa yang mengalami quarter-life crisis. Sehingga, dapat disimpulkan bahwa tingginya tingkat emotional intelligence pada mahasiswa yang mengalami quarter-life crisis, maka semakin rendah tingkat stresnya. Sedangkan, rendahnya tingkat emotional intelligence pada mahasiswa yang mengalami quarter-life crisis, maka semakin tinggi tingkat stresnya.
\end{abstract}

Kata kunci: Dewasa Awal, Emotional Intelligence, Quarter Life Crisis, Stres

\begin{abstract}
The purpose of this study was to determine the relationship between emotional intelligence levels and stress levels in students who experienced a quarter life crisis. The hypothesis proposed is that there is a negative relationshipbetween the level of emotional intelligence and the level of stress in students who experience a quarter life crisis. This study is a quantitative study involving 100 students who are still in early adulthood with an age range of 20 to 30 years. Data collection was carried out using 2 scales, namely the emotional intelligence and stress scale. The data were analyzed using the Statistical Package for Social Science 25 program for windows version with the product moment correlation technique. The results of data analysis showed a correlation value of -0.643 with a significance level of 0.000 ( $p<0.05)$. This can be interpreted that emotional intelligence is negatively and significantly related to stress in students who experience a quarter-life crisis. Thus, it can be concluded that the higher the level of emotional intelligence in students who experience a quarter-life crisis, the lower the stress level. Meanwhile, the lower the level of emotional intelligence in students who experience a quarter-life crisis, the higher the stress level.
\end{abstract}

Keywords : Early Adulthood, Emotional Intelligence, Quarter Life Crisis, Stress

\section{PENDAHULUAN}

Pada hakikatnya, setiap individu pasti memiliki tugas perkembangan yang harus terpenuhi disetiap tahapannya. Karakteristik pada setiap tahapan perkembangan pun sangat beragam. Individu yang sudah mempersiapkan diri untuk menjalani perubahan - perubahan di setiap tugasnya, akan berkembang menuju kedewasaan. Disamping itu, individu yang kurang mampu menghadapi perubahan pada fase ini akan merasa sulit dan penuh kekhawatiran akan hal yang terjadi pada saat masa dewasa awal. Hal ini biasa terjadi pada mahasiswa yang secara umum tergolong dalam masa dewasa awal. Salah 
satu contohnya adalah pengambilan keputusan mengenai kelanjutan pendidikan, karir, dan pasangan hidup menjadi hal yang membuat dilema mahasiswa itu sendiri di masa dewasa awal. Dewasa awal merupakan masa peralihan dari masa remaja. Hurlock dkk, (2007) membagi tahapan perkembangan dewasa menjadi tiga kelompok usia, yaitu: masa dewasa awal yang terjadi pada rentang usia 20-35 tahun, masa dewasa madya yang terjadi pada rentang usia 3560 tahun, dan dewasa akhir yang terjadi pada usia 60 hingga akhir hayat (dalam Hapsari \& Kurniawan, 2019). Individu yang gagal dalam memenuhi tugas perkembangan pada masa ini dapat disebabkan oleh beberapa faktor seperti, peran baru yang membuatnya tidak siap, kurang mampu beradaptasi dengan peran baru, serta tidak adanya dukungan dari lingkungan sekitar (Jahja, 2011). Hal ini sejalan dengan pendapat yang dikemukakan Wood et al (dalam Habibie dkk, 2018), bahwa masa emerging adulthood adalah masa - masa eksplorasi bagi tiap individu yang berada pada masa dewasa awal.

\section{Masa emerging adulthood} berlangsung pada rentang usia $18-29$ tahun. Di masa ini, individu dipandang mampu untuk tidak bergantung pada orang tua layaknya saat remaja.
Walaupun, mereka belum memasuki masa menjalankan tanggung jawab orang dewasa seperti bekerja, menikah, dan lain sebagainya. Masa peralihan ini dirasa krusial bagi mereka dikarenakan pada saat ini individu mulai menggali diri lebih jauh pada bidang akademik, pekerjaan, berdikari, mengemban peran sosial, serta menghasilkan rekanan terhadap lawan jenis. Area eksplorasi yang luas membuat individu banyak menghadapi perubahanperubahan yang bisa memberikan dampak terhadap perasaan tidak nyaman dalam dirinya yang menyebabkan timbulnya ketidakstabilan emosi (Arnet, dalam Rosalinda \& Michael, 2019).

Kurang stabilnya

emosi

mengakibatkan munculnya perbedaan reaksi antar individu. Hal ini dijelaskan oleh Nash dan Murray (2010) bahwa terdapat individu yang merasa antusias, karena merasa tertantang dengan kondisi baru yang belum pernah dirasakan sebelumnya. Akan tetapi, beberapa dari mereka juga merasakan kecemasan, kekhawatiran dan merasa hampa. Individu yang merespon negatif masalah yang muncul pada tahapan perkembangan, kemungkinan dapat mengalami beragam permasalahan psikologis seperti, rasa dilema pada ketidakpastian dan mengalami krisis emosional atau sering dikenal sebagai quarter life crisis. 
(Atwood \& Scholtz, dalam Habibie dkk, 2018).

Black (dalam Cahya, 2020) mendefinisikan quarter-life crisis sebagai reaksi individu terhadap ketidakstabilan yang maksimal sebagai dampak dari perubahan yang tetap dan beragam pilihan yang disertai oleh perasaan panik serta kurang berdaya. Quarter-life crisis merupakan perasaan khawatir terhadap kehidupan masa depan dimana sangat berhubungan dengan pekerjaan dan kehidupan sosial, yang ditandai dengan timbulnya emosi seperti panik, khawatir, serta hilang arah pada remaja sekolah menengah keatas. Hal ini dapat mengarahkan individu mengalami stres atau gangguan psikologis, yang biasa muncul di sekitar usia 20 sampai 29 tahun. Rasa cemas yang timbul karena tidak bisa memprediksi kehidupan masa depan seputar relasi, karier, dan kehidupan sosial biasa terjadi pada usia 20-an (Fischer, 2008).

Sejalan dengan pernyataan di atas, Thouless (2000) menjelaskan bahwa terdapat dua faktor penyebab quarter-life crisis yaitu faktor internal dan faktor eksternal. Adapun faktor internal meliputi pengalaman pribadi, moral, faktor emosi dan afeksi, serta faktor intelektual. Sedangkan faktor eksternal meliputi kondisi sosial dan lingkungan, tingkat pendidikan, tradisi, budaya serta tuntutan sehari-hari. Dalam penelitian Allison (2010), menyebutkan bahwa respon emosional yang muncul selama fase quarter life crisis di usia 20 - 29 tahun ialah dilema, cemas, panik dan gelisah. Gejolak emosional yang dibiarkan berlangsung lama dapat menyebabkan munculnya hal negatif di kehidupannya seperti stres dan depresi. Hal ini kerap dialami oleh mahasiswa yang berada pada fase quarter-life crisis, yang ditandai dengan perasaan dilema, cemas, panik, dan gelisah dalam memikirkan kelanjutan pendidikan, karir di masa mendatang, maupun membangun relasi dengan lawan jenis. Perilaku yang ditunjukkan antara lain, sulit berkonsentrasi saat mengerjakan suatu hal, menarik diri dari lingkungan, hilangnya nafsu makan yang merupakan tanda - tanda stres (Sarafino, 2006).

Di samping itu, Selye (dalam Fink, 2010), menyebutkan stres merupakan respon tubuh yang spesifik terhadap penyebab stressor yang bisa berpengaruh pada individu. Sedangkan Gadzella dan Masten (dalam Septiani dan Fitri, 2016) menyatakan bahwa pengalaman kurang bahagia yang dilalui oleh individu terjadi karena beragam stresor seperti dilema, konflik, tekanan, perubahan, dan merasa terbebani. Hal ini menyebabkan timbulnya beragam reaksi seperti perubahan 
fisiologis, emosi, tingkah laku, dan irrasional believe terhadap stres yang dialami individu. Reaksi pada tiap individu sangat bervariasi, beberapa dari mereka merespon keadaan dengan reaksi fisiologis. Di lain hal, terdapat individu yang berdampak pada perubahan perilaku seperti perilaku maladaptif, serta tak sedikit pula yang memunculkan emosi seperti rasa sedih, cemas dan tertekan.

Salah satu faktor yang menunjang kemampuan beradaptasi agar terhindar dari kondisi stres adalah kecerdasan emosi. Pada tahap quarter-life crisis, individu masih mempunyai pengalaman emosional yang terbatas, sehingga membuatnya rentan terkena stres. Hal ini sejalan dengan pendapat yang disampaikan oleh Adeyemo \& Ogunyemi (dalam Issom \& Aprilia, 2019), bahwa agar terhindar dari stres, individu diminta untuk dapat menyesuaikan diri dengan lingkungannya yang baru, layaknya kecerdasan emosional yang baik.

Bar On (Megawati, 2010; dalam Kartika, C. D., 2015) mendefinisikan emotional intelligence sebagai rangakaian kemampuan pribadi, emosi dan sosial yang dapat berpengaruh pada kemampuan individu dalam mengatasi tuntutan dan tekanan lingkungan. Sedangkan menurut Goleman (2001) emotional intelligence diartikan sebagai keahlian untuk mengidentifikasi perasaan (diri sendiri maupun orang lain), keahlian memotivasi diri sendiri, keahlian mengatur emosi dengan baik pada diri sendiri maupun dalam membangun relasi. Kecerdasan emosi adalah hal penting yang seharusnya ada di dalam diri individu tertuama untuk mengantisipasi stressfull event pada tahap quarter-life crisis, seperti mampu mengenali emosi dalam diri dan memotivasi diri sendiri. Hal ini dapat membuat individu mampu mengenali emosi dalam dirinya maupun lingkungan sekitarnya.

Berdasarkan penjelasan tersebut, peneliti tertarik untuk melakukan penelitian yang terkait dengan tingkat emotional intelligence dan tingkat stres pada mahasiswa yang mengalami quarterlife crisis.

\section{KAJIAN PUSTAKA}

Fischer (2008) menyatakan bahwa quarter-life crisis adalah perasaan yang timbul pada individu yang memasuki usia pertengahan 20-an tahun, dimana muncul rasa takut akan kehidupan di masa depan. Quarter-life crisis juga dapat diartikan sebagai munculnya respon negatif dan krisis emosional pada individu yang memasuki usia 20-an tahun, seperti perasaan tak berdaya, terisolasi, ragu terhadap kemampuan diri sendiri, dan 
takut akan kegagalan. Sehingga dapat disimpulkan bahwa quarter-life crisis adalah perasaan yang muncul pada individu yang menginjak usia 20 -an tahun seperti, rasa takut akan masa depan dan juga takut akan gagal. Tahapan quarterlife crisis menurut Robinson (2011), terdapat lima fase yang dilalui oleh individu dalam quarter-life crisis, yaitu:

a. Fase pertama, munculnya perasaan terjebak dalam berbagai macam pilihan serta tidak mampu memutuskan apa yang harus dijalani dalam hidup.

b. Fase kedua, adanya dorongan yang kuat untuk mengubah situasi.

c. Fase ketiga, melakukan tindakan tindakan yang sangat krusial, seperti keluar dari pekerjaan lama untuk mencoba pengalaman baru.

d. Fase keempat, membangun pondasi baru dimana individu dapat mengendalikan arah tujuan kehidupannya.

e. Fase kelima, membangun kehidupan abru yang lebih fokus pada hal - hal yang memang menjadi minat dan nilai moral yang dipercaya oleh individu tersebut.

Pengertian Stres

Selye, (1950) mendefinisikan stres sebagai respon tubuh yang secara spesifik terhadap stresor yang mempengaruhi individu. Selye (dalam Husmiati, 2020) menjelaskan respon tubuh terhadap stres disebut dengan istilah sindrom adaptasi umum atau dikenal juga dengan istilah GAS (General Adaptation Syndrome). Sehingga dapat disimpulkan bahwa stres adalah reaksi tubuh yang dapat mempengaruhi individu dalam beradaptasi.

Aspek Stres

Menurut Selye (dalam Aristawati, 2016) terdapat empat aspek dalam stres, yaitu:

a. Aspek fisik, seperti keadaan fisik yang lemah, pusing, banyak berkeringat, percepatan denyut jantung.

b. Aspek kognitif, seperti mudah lupa, sulit berkonsentrasi, menurunnya daya ingat.

c. Aspek emosi, seperti ketakutan berlebih, mudah marah, gugup, sedih berkepanjangan.

d. Aspek perilaku seperti, engga melakukan pekerjaan, menyendiri, kehilangan nafsu makan.

Pengertian Emotional Intelligence

Salovey dan Mayer

(2003)

mendefinisikan emotional intelligence sebagai kemampuan indivu dalam memilah dan menggunakan informasi untuk mengembangkan pikiran dan memutuskan tindakan yang dapat mempengaruhi emosi pada diri individu 
tersebut. Goleman pada tahun 2017 (dalam Swantara \& Supriyadi 2020) menjelaskan bahwa emotional intelligence merupakan kemampuan individu untuk mengendalikan diri, memiliki daya tahan ketika menghadapi suatu masalah, memotivasi diri, mampu mengatur suasana hati, kemampuan berempati dan juga mampu membina hubungan yang baik dengan orang lain. Sehingga dapat disimpulan bahwa emotional intelligence adalah kemampuan seseorang untuk mengendalikan diri, memiliki daya tahan saat menghadapi masalah, membuat keputusan yang dapat mempengaruhi hubungan sosial individu tersebut.

Aspek Emotional Intelligence

$$
\text { Goleman (1999) membagi }
$$

emotional intelligence dalam lima aspek, yaitu:

a. Aspek kesadaran diri, seperti mampu mengenali karakteristik diri, emosi dalam diri, waspada akan perasaan dalam diri.

b. Aspek pengaturan diri, seperti mampu menghibur diri, melepaskan kecemasan, mengekspresikan emosi yang tepat.

c. Aspek motivasi, seperti bertanggung jawab, mampu fokus pada tugas yang sedang dikerjakan.

d. Aspek empati, seperti, mampu mengerti suasana hati individu lain dan mengerti permasalahan individu lain.

e. Aspek keterampilan sosial, mampu menjalin komunikasi baik dengan individu lain.

\section{METODE PENELITIAN}

Penelitian ini menggunakan metode kuantitatif korelasi. Hal ini berguna untuk mengetahui hubungan antara tingkat emotional intelligence dengan tingkat stres pada mahasiswa yang mengalami quarter-life crisis. Subjek dalam penelitian ini ditentukan dengan teknik purposive sampling sehingga didapatkan subjek sebanyak 100 orang mahasiswa yang berusia antara 20 hingga 30 tahun dan belum menikah. Data dikumpulkan melalui 2 macam skala, yaitu skala stres dan skala emotional intelligence. Kemudian, data dianalisis menggunakan bantuan program Statistic Package for Social Science 25 for Windows version dengan teknik korelasi product moment.

\section{HASIL DAN PEMBAHASAN}

Berdasarkan hasil penelitian dapat diketahui gambaran subjek penelitian berdasarkan jenis kelamin, latar belakang pendidikan, dan status pekerjaan sebagai berikut: 
Tabel 1. Gambaran Subyek Penelitian

\begin{tabular}{|c|c|c|}
\hline Kategori & $\mathbf{F}$ & $(\%)$ \\
\hline Jenis kelamin & & \\
\hline Pria & 31 & $31 \%$ \\
\hline Wanita & 69 & $69 \%$ \\
\hline Status Pekerjaan & & \\
\hline Bekerja & 70 & $70 \%$ \\
\hline Tidak Bekerja & 30 & $30 \%$ \\
\hline
\end{tabular}

diketahui bahwa sebaran subjek penelitian berdasarkan jenis kelamin, lebih banyak wanita dibandingkan pria. Subjek pria berjumlah 31 orang (31\%) sedangkan subjek wanita berjumlah 69 orang (69\%). Selanjutnya status pekerjaan didominasi dengan yang bekerja dibandingkan yang tidak bekerja. Dapat dilihat pada tabel 1, ada 70 orang $(70 \%)$ yang bekerja, sedangkan 30 orang (30\%) yang tidak bekerja.

Kategorisasi Stres

Berdasarkan data yang diperoleh, dapat dilakukan pengkategorian tingkat stres pada individu yang mengalami quarter-life crisis. Adapun hasil pengkategoriaan tingkat stres adalah sebagai berikut:

Tabel 2. Kategori Tingkat Stres

\begin{tabular}{lccc}
\hline Kategori & Range & N & \% \\
\hline $\begin{array}{l}\text { Sangat } \\
\text { Tinggi }\end{array}$ & $98-106$ & 4 & $4 \%$ \\
\hline Tinggi & $82-97$ & 23 & $23 \%$ \\
\hline Sedang & $65-81$ & 46 & $46 \%$ \\
\hline Rendah & $49-64$ & 23 & $23 \%$ \\
\hline $\begin{array}{l}\text { Sangat } \\
\text { Rendah }\end{array}$ & $41-48$ & 4 & $4 \%$ \\
\hline Total & & $\mathbf{1 0 0}$ & $\mathbf{1 0 0 \%}$ \\
\hline \multicolumn{1}{c}{ Berdasarkan } & tabel 2 & diketahui
\end{tabular}

bahwa subjek penelitian dapat digolongkan dalam 5 kategori stres, yakni kategori sangat rendah sebesar 4\% (4 orang), kategori rendah sebesar 23\% (23 orang), kategori sedang sebesar $46 \%$ (46 orang), kategori tinggi sebesar 23\% (23 orang) dan kategori sangat tinggi sebesar $4 \%$ (4 orang).

Kategorisasi Emotional Intelligence

Selain itu, berdasarkan data yang diperoleh, juga dapat dilakukan pengkategorian tingkat emotional intelligence pada subjek penelitian dilakukan dengan tujuan untuk memberikan gambaran sebaran tingkat emotional intelligence pada individu yang mengalami quarter-life crisis. Adapun hasil pengkategoriaan tingkat emotional intelligence adalah sebagai berikut:

Tabel 3. Kategori Tingkat Emotional Intelligence

\begin{tabular}{lccc} 
Kategori & Range & N & $\%$ \\
\hline $\begin{array}{l}\text { Sangat } \\
\text { Tinggi }\end{array}$ & $138-150$ & 6 & $6 \%$ \\
\hline Tinggi & $121-137$ & 20 & $20 \%$ \\
\hline Sedang & $104-120$ & 51 & $51 \%$ \\
\hline Rendah & $87-103$ & 19 & $19 \%$ \\
\hline $\begin{array}{l}\text { Sangat } \\
\text { Rendah }\end{array}$ & $76-86$ & 4 & $4 \%$ \\
\hline Total & - & $\mathbf{1 0 0}$ & $\mathbf{1 0 0 \%}$ \\
\hline \multicolumn{5}{c}{ Berdasarkan } & tabel 3 & diketahui \\
bahwa & subjek & penelitian & dapat \\
digolongkan dalam & 5 & kategori & yakni \\
kategori sangat rendah & sebesar & $4 \%$ & $(4$ \\
orang), kategori rendah sebesar & $19 \%$ & $(19$ \\
orang), kategori sedang & sebesar & $51 \%$ & $(51$ \\
orang), kategori tinggi & sebesar & $20 \%$ & $(20$
\end{tabular}


orang) dan kategori sangat tinggi sebesar $6 \%$ (6 orang).

Hasil Uji Korelasi

Pembuktian untuk menjawab adanya hipotesis dalam penelitian ini dilakukan uji korelasi dengan teknik korelasi product moment dengan bantuan program SPSS 25 for Windows. Adapun hasil uji korelasi adalah sebagai berikut:

Tabel 4. Uji Korelasi

\begin{tabular}{|c|c|c|c|}
\hline & & $\begin{array}{l}\text { Emotional } \\
\text { Intelligence }\end{array}$ & Stres \\
\hline \multirow{3}{*}{$\begin{array}{l}\text { Emotional } \\
\text { Intelligence }\end{array}$} & $\begin{array}{l}\text { Korelasi } \\
\text { Pearson }\end{array}$ & 1 & $-0,643$ \\
\hline & $\begin{array}{l}\text { Sig. } \\
\text { (2-tailed) }\end{array}$ & & 0.000 \\
\hline & Jumlah & 100 & 100 \\
\hline \multirow{3}{*}{ Stres } & $\begin{array}{l}\text { Korelasi } \\
\text { Pearson }\end{array}$ & $-0,643$ & 1 \\
\hline & $\begin{array}{l}\text { Sig. } \\
\text { (2-tailed) }\end{array}$ & 0.000 & \\
\hline & Jumlah & 100 & 100 \\
\hline
\end{tabular}

Product Moment dapat diketahui bahwa nilai korelasi adalah $-0,643$ dengan taraf signifikansi $p=0,000 \quad(p<0,05)$. Hal ini dapat diartikan bahwa emotional intelligence berhubungan negatif dan signifikan terhadap stres pada mahasiswa yang mengalami quarter-life crisis. Sehingga, dapat dikatakan bahwa tingginya tingkat emotional intelligence pada mahasiswa yang mengalami quarterlife crisis, maka semakin rendah tingkat stresnya. Sedangkan, rendahnya tingkat emotional intelligence pada mahasiswa yang mengalami quarter-life crisis, maka semakin tinggi tingkat stresnya.

\section{Pembahasan}

Hasil penelitian menunjukkan terdapat korelasi negatif dan signifikan antara tingkat emotional intelligence dengan tingkat stres pada mahasiswa yang mengalami quarter-life crisis. Hal ini berarti tingginya tingkat emotional intelligence pada mahasiswa yang mengalami quarter-life crisis, maka semakin rendah tingkat stresnya. Sedangkan, rendahnya tingkat emotional intelligence pada mahasiswa yang mengalami quarter-life crisis, maka semakin tinggi tingkat stresnya. Hasil penelitian ini juga menyampaikan informasi mengenai data sumbangan efektif yang diberikan oleh emotional intelligence sebesar $41,34 \%$ terhadap tingkat stres pada mahasiswa yang mengalami quarter-life crisis. Hasil ini juga menggambarkan adanya 58,66\% variabel lain yang tidak diteliti dalam penelitian, seperti efikasi diri, faktor internal maupun eksternal lainnya (Afnan, dkk., 2020). Hal ini didukung oleh penelitian yang dilakukan oleh Issom \& April (2019), yang menjelaskan bahwa adanya pengaruh negatif dan signifikan antara kecerdasan emosi dengan stres.

Tak hanya itu, penelitian lain yang dilakukan Kartika C.D. (2015) juga menyampaikan bahwa ada hubungan 
negatif yang signifikan antara kecerdasan emosi dengan stres. Di samping itu, penelitian yang dilakukan oleh Baharuddin, dkk (2020) juga menyebutkan bahwa ada hubungan negatif yang signifikan antara keceradasan emosi dengan stres. Mahasiswa yang sedang mengalami quarter-life crisis memiliki tingkat stres yang rendah. Hal ini membuktikan bahwa penilaian positif yang dimiliki mahasiswa, membuatnya dapat melewati tantangan dan perubahan tugas perkembangan saat mengalami quarter-life crisis. Mahasiswa dinilai mampu untuk beradaptasi dengan atmostfer baru saat menginjak usia dewasa awal. Hal ini didukung dengan teori yang disampaikan oleh Selye (dalam Fink, 2010) bahwa stres merupakan korelasi antara individu dengan lingkungan atau kondisi yang diprediksi sebagai tuntutan dan ketidakmampuan. Penilaian individu sangat berpengaruh terhadap seimbang tidaknya permintaan lingkungan dengan kesiapan individu, sehingga dapat menjadi poin utama penentu tingkat stres yang dialami saat berhadapan dengan situasi yang tidak mudah.

Sementara itu, hasil penelitian ini juga menunjukkan bahwa mahasiswa yang mengalami quarter-life crisis akan memiliki emotional intelligence yang tinggi karena pada umumnya, individu yang menginjak dewasa awal mempunyai tingkat tanggung jawab yang tinggi serta lebih berkonsentrasi dalam hal mengerjakan tugas maupun menyelesaiakan pekerjaannya (Goleman, 1999). Hal ini didukung dengan pernyataan yang dikemukakan oleh Goleman (2017) bahwa individu dengan tingkat kecerdasan emosi yang baik adalah individu yang dapat mengontrol emosi dalam diri dengan baik antar individu lainnya, seperti keahlian dalam memahami orang lain, mampu memotivasi diri serta mahir dalam membuat kerjasama dengan orang lain. Kecerdasan emosi menjadi faktor utama dalam mengendalikan emosi, karena berhubungan dengan cara memutuskan, bertindak, dan berperilaku. Walaupun demikian, kecerdasan emosi pada setiap individu memiliki tingkatan yang beragam. Menurut Swadnyana dan Tobing (dalam Swantara \& Supriyadi, 2020), individu pada fase quarter-life crisis yang mempunyai kecerdasan emosi yang tinggi, mampu mengelola emosi dengan baik, sedangkan individu pada fase quarter-life crisis yang mempunyai kecerdasan emosi yang rendah dapat membuatnya merasa stres atau terkena gangguan psikologis lainnya. 


\section{PENUTUP}

\section{Kesimpulan}

Berdasarkan hasil penelitian, didapatkan kesimpulan bahwa emotional intelligence berhubungan negatif dan signifikan terhadap stres pada mahasiswa yang mengalami quarter-life crisis. Sehingga, dapat dikatakan bahwa tingginya tingkat emotional intelligence pada mahasiswa yang mengalami quarterlife crisis, maka semakin rendah tingkat stresnya. Sedangkan, rendahnya tingkat emotional intelligence pada mahasiswa yang mengalami quarter-life crisis, maka semakin tinggi tingkat stresnya.

\section{Saran}

Saran yang dapat diberikan berdasarkan hasil penelitian ini adalah sebagai berikut:

a. Bagi Subjek Penelitian

Mahasiwa yang mengalami quarter life crisis disarankan untuk mengembangkan kecerdasan emosi yang dipunyai dalam melewati rintanganrintangan pada fase ini sehingga dapat sehat secara psikologis.

b. Bagi Pendidik atau Orang Tua

Orang tua mampu membimbing anaknya seperti menggambarkan dan memberikan saran yang berkaitan dengan peran baru di usia dewasa awal ketika mengalami fase quarter life crisis. Selain itu, bagi pendidik, terutama pada jenjang sarjana/diploma dapat membuat inovasi baru melalui program pelatihan-pelatihan psikologi untuk mempersiapkan para mahasiswa agar siap menghadapi masa quarter-life crisis dalam kehidupannya.

c. Bagi Peneliti Selanjutnya

Peneliti selanjutnya yang memiliki keinginan melakukan penelitian sejenis, diharapkan dapat menambah jumlah sampel agar hasil penelitian mendapatkan hasil yang lebih akurat. Selain itu, perlu mempertimbangkan variabel-variabel lain yang dapat mempengaruhi stres pada individu yang mengalami quarter life crisis.

\section{DAFTAR PUSTAKA}

Afnan, A., Fauzia, R., \& Tanau, M. U. 2020. Hubungan Efikasi Diri Dengan Stress Pada Mahasiswa Yang Berada Dalam Fase Quarter Life Crisis. Jurnal Kognisia: Jurnal Mahasiswa Psikologi Online, 3(1), 23-29.

Anggawira, A. 2019. Hubungan Adversity Quotient Dan Stres Pada Siswa Kelas Xii Yang Akan Mengikuti Ujian Nasional di SMAN 1 Padang. Psyche 165 Journal, 12(1), 64-69. doi: 10.29165/psikologi.v12i1.66

Agustin, I. 2012. Terapi Dengan Pendekatan Solution-Focused Pada Individu Yang Mengalami Quarter Life Crisis. Universitas Indonesia. (Tesis tidak dipublikasikan). Depok: Universitas Indonesia.

Aristawati, A. R. 2016. Stress Dan Perilaku Agresi Pada Ibu Rumah Tangga Yang Tidak Bekerja di 
Surabaya. Persona: Jurnal Psikologi Indonesia, 5(02).

Azmy, A. N., Nurihsan, A. J., \& Yudha, E.S. 2017. Deskripsi Gejala Stres Akademik Dan Kecenderungan Pilihan Strategi Koping Siswa Berbakat. Indonesian Journal of Educational Counseling, 1(2), 197208.

Baharuddin, M. I., Jufri, M., \& Hamid, A.N. 2020. Hubungan Antara Kecerdasan Emosi Dengan Stres Kerja Pada Anggota Kepolisian Satuan Lalu Lintas Polrestabes Makassar. Jurnal Psikologi TALENTA, 5(1), 67-77.

Brebahama, A., \& Listyandini, R. A. 2017. Gambaran Tingkat Kesejahteraan Psikologis Penyandang Tunanetra Dewasa Muda. Mediapsi, 2(1), 1-10.

Bustan, R. 201. Persepsi Dewasa Awal Mengenai Kursus Pranikah. Jurnal Al- Azhar Indonesia Seri Humaniora, 3(1), 82-95.

Habibie, A., Syakarofath, N. A., \& Anwar, Z. 2019. Peran Religiusitas terhadap Quarter-Life Crisis (QLC) pada Mahasiswa. Gadjah Mada Journal of Psychology (GamaJoP), 5(2), 129- $138 . \quad$ doi: 10.22146/gamajop. 48948

Hapsari, A., \& Kurniawan, A. 2019. Efektivitas Cognitive Behaviour Therapy (CBT) Untuk Meningkatkan Kualitas Tidur Penderita Gejala Insomnia Usia Dewasa Awal. Jurnal Ilmu Keluarga \& Konsumen, 12(3), 223235.

Husmiati, H. 2018. Stres Kerja Dari Perspektif Teori Sistem-Ekologi. Sosio Informa, 4(3).
Intani, Z. F., \& Indati, A. 2017. Peranan Wisdom Terhadap Subjective WellBeing Pada Dewasa Awal. Gadjah Mada Journal of Psychology (GamaJoP), 3(3), 141-150.

Issom, F. L., \& Aprilia, F. 2019. Pengaruh Kecerdasan Emosi Terhadap Stres Kerja Pada Pengajar Muda Di Gerakan Indonesia Mengajar. JPPPJurnal Penelitian dan Pengukuran Psikologi, 8(1), 1-11.doi: 10.21009/JPPP.081.01

Jahja, Y. 2011. Psikologi Perkembangan. Jakarta: Kencana.

Kartika, C. D. 2015. Hubungan Antara Kecerdasan Emosi Dengan Stres Akademik Mahasiswa Fakultas Psikologi Universitas Muhammadiyah Surakarta. (Skripsi tidak dipublikasikan). Surakarta: Universitas Muhammadiyah Surakarta.

Kirnandita, P. 2019. Quarter Life Crisis: Kehidupan Dewasa Datang, Krisis pun Menghadang. Diakses melalui https://tirto.id/quarter-life-crisiskehidupan-dewasa-datang-krisispun-menghadang-dkvU (pada tanggal 7 November 2020).

Latipah, E. 2014. Metode Penelitian Psikologi Pendidikan. Yogyakarta: Deepublish.

Lestari, S. D., \& Hertinjung, W. S. 2017. Hubungan Antara Kecerdasan Emosional Dengan Stres Dalam Menyusun Skripsi Pada Mahasiswa Fakultas Psikologi Universitas Muhammadiyah Surakarta. (Skripsi tidak dipublikasikan). Surakarta: Universitas Muhammadiyah Surakarta.

Lumban Gaol, N. T. 2016. Teori Stres: Stimulus, Respons, Dan 
Transaksional. Bul Psikol, 24(1), 111.

Permana, B. I. 2020. Quarter Life Crisis Biasa Dialami Usia 20 Tahun ke Atas, Rachel Amanda Merasakannya di Umur Belasan. Diakses melalui https://www.tribunnews.com/lifestyl e/2020/06/26/quarter-life-crisisbiasa-dialami-usia-20-tahun-keatas- rachel-amandamerasakannya-di- umur-belasan. (pada tanggal 7 November 2020).

Riduwan \& Akdon. 2010. Rumus dan Data dalam Analisis Data Statistika. Bandung: Alfabeta.

Septiani, T., \& Fitria, N. 2017. Hubungan Antara Resiliensi Dengan Stres Pada Mahasiswa Sekolah Tinggi Kedinasan. Jurnal Penelitian Psikologi, 7(2), 59-76. Diakses melaui http://jurnalfpk.uinsby.ac.id/index.p hp/JPP/article/view/59 (pada tanggal 9 November 2020).

Swadnyana, I., \& Tobing, D. H. 2019. Hubungan Antara Kecerdasan Emosional Dan Agresivitas Pada Remaja Madya di SMA Dwijendra Denpasar. Jurnal Psikologi Udayana, 6(2), 1125-1134.

Swantara, M. S., \& Supriyadi, S. 2020. Peran Religiusitas Dan Kecerdasan Emosional Terhadap Agresivitas Remaja Madya di SMA Negeri Denpasar. Jurnal Psikologi Udayana, 37-48. Diakses melalui https://ocs.unud.ac.id/index.php/psik ologi/article/view/63493 （pada tanggal 10 November 2020 